\title{
O SISTEMA DE GESTÃO AMBIENTAL COMO ESTRATÉGIA DA EDUCAÇÃO AMBIENTAL NO SENAC DE SÃO JOSÉ DOS CAMPOS (SP)
}

\author{
Marcos Camargo de Aguiar ${ }^{1}$ \\ Denise Regina da Costa Aguiar² \\ Cristina Veloso de Castro ${ }^{3}$
}

Resumo: $O$ presente trabalho busca promover a discussão sobre a possibilidade de o sistema de gestão ambiental ser integrado na dinâmica escolar como estratégia da Educação Ambiental no SENAC São José dos campos/SP. Para isso, são abordadas as características, princípios e formas de implantação do sistema de gestão ambiental com vistas à sustentabilidade, de modo a articulá-lo à atividade educacional. Foi realizada uma pesquisa documental e questionários com o objetivo de se obter a representação social dos professores e alunos da escola, sobre a integração do sistema de gestão ambiental com a prática educacional. Nesse contexto, uma preocupação essencial é como as práticas de gestão ambiental podem promover a reflexão e conscientização de todos os envolvidos, integrando-se no sistema de ensino das escolas.

Palavras-chave: Preservação Ambiental; Prática Pedagógica; Conscientização.

1 Universidade Brasil. E-mail: camargopmk@gmail.com

2 Universidade Brasil. E-mail: costaag@uol.com.br

3 Universidade Brasil. E-mail: cristina.castro@universidadebrasil.edu.br 


\section{Introdução}

Este artigo é resultado de um recorte da dissertação de mestrado junto ao Programa de Pós-Graduação - Mestrado em Ciências Ambientais da Universidade Brasil, cujo objetivo geral foi: investigar a possibilidade de o sistema de gestão ambiental ser integrado na dinâmica escolar como estratégia da Educação Ambiental no SENAC São José dos campos (SP).

A presente pesquisa buscou analisar criticamente o Sistema de Gestão Ambiental como estratégia para a prática pedagógica da Educação Ambiental nos cursos técnicos do Serviço Nacional de Aprendizagem Comercial (SENAC) de São José dos Campos/SP, e a partir disso, propor uma intervenção com os docentes e discentes de maneira a sensibilizar, fomentar o debate, a participação, para uma tomada de consciência que possibilite uma maior compreensão do mundo em que vivem, dos contextos sociais, econômicos e ambientais, com projetos e ações que contribuam para a preservação do meio ambiente, para a construção de uma sociedade mais justa e humana.

A análise crítica dos projetos de Educação Ambiental nos cursos técnicos foi realizada através da análise documental, de alguns projetos elaborados e desenvolvidos, além dos questionários, que foram aplicados com os docentes e discentes envolvidos no processo. A partir dos resultados, foi desenvolvida uma proposta de intervenção como subsídio, um caminho possível para a reorientação das práticas pedagógicas frente à Educação Ambiental em uma perspectiva crítica e emancipatória.

A questão ambiental é um tema de grande relevância, a prática pedagógica em sala de aula é fundamental para possibilitar a construção de conhecimentos e contribuir com a tomada de consciência de educadores e educandos, em relação à formação do cidadão comprometido com as questões ambientais e sociais. Assim, partir do senso comum, dos saberes e experiências dos educandos para a construção de novos saberes, do conhecimento científico.

Em razão de a Educação Ambiental estar diretamente ligada ao modo de vida das pessoas, como vivem e convivem em sociedade, é necessário que o ambiente onde se viva seja percebido em sua totalidade, suas características e seus problemas, buscando possibilitar a tomada de consciência do educador e do educando, de seu papel na sociedade, construindo a solidariedade, respeito, a justiça social e ambiental.

A Constituição Federal de 1988 expressa em seu texto legal, no artigo 205 a garantia do direito a educação e a formação integral do educando, princípio da vida humana.

Art.205: A educação, direito de todos e dever do Estado e da família, será promovida e incentivada com a colaboração da sociedade, visando ao pleno desenvolvimento da pessoa, seu preparo para o exercício da cidadania e sua qualificação para o trabalho (BRASIL, 1988)

revista brasileira educação ambiental 
E no inciso VI do $\S 1^{\circ}$ do artigo 225 determina que o Poder Público deve promover a Educação Ambiental em todos os níveis de ensino, pois "todos têm direito ao meio ambiente ecologicamente equilibrado, bem de uso comum do povo e essencial à sadia qualidade de vida, impondo-se ao poder público e à coletividade o dever de defendê-lo e preservá-lo para as presentes e futuras gerações".

As Diretrizes Curriculares Nacionais para a Educação Ambiental (2012) estabelecem, no artigo $2^{\circ}$, que:

A Educação Ambiental é uma dimensão da educação, é atividade intencional da prática social, que deve imprimir ao desenvolvimento individual um caráter social em sua relação com a natureza e com os outros seres humanos, visando potencializar essa atividade humana com a finalidade de torná-la plena de prática social e de ética ambiental. (BRASIL, 2012)

E, no artigo 3o que: a Educação Ambiental visa à construção de conhecimentos, ao desenvolvimento de habilidades, atitudes e valores sociais, ao cuidado com a comunidade de vida, a justiça e a equidade socioambiental, e a proteção do meio ambiente natural e construído.

Assim, os princípios legais têm contribuído para os sistemas de ensino repensarem seus objetivos e buscarem inovações para conseguir formar novas habilidades e valores que ajudem o educando a entender a sociedade local e global, posicionar-se de forma crítica frente aos problemas sociais e ambientais que o cercam para superá-los.

Neste contexto, procura-se justificar a proposição de um projeto de educação integrado ao Sistema de Gestão Ambiental da unidade do SENAC São José dos Campos/SP, que visa uma tomada de consciência crítica sobre os fatores naturais, científicos e sociais que compõem a problemática ambiental, desenvolvido de forma participativa e dialógica, caracterizado por trocas de experiências, em uma abordagem interdisciplinar, que contribua com a formação da cidadania consciente e crítica.

\section{Metodologia}

A pesquisa foi desenvolvida por meio de uma abordagem qualitativa. Denzin e Lincoln (2006) enfatizam que, na abordagem qualitativa, há um contato direto do pesquisador com o ambiente e a situação que está sendo investigada.

O primeiro passo da metodologia utilizada foi à pesquisa bibliográfica em livros, dissertações, teses e pesquisa de campo no SENAC São Jose dos Campos/SP. Posteriormente foi realizada pesquisa documental e aplicação de questionários com o objetivo de se coletar dados com os educadores e educandos da escola, sobre a integração do Sistema de Gestão Ambiental com a prática pedagógica da Educação Ambiental. Finalmente, foram tecidas 
algumas considerações sobre o Sistema de Gestão Ambiental como estratégia educacional para a construção de uma proposta de intervenção como subsídio, um caminho possível para a reorientação das práticas pedagógicas frente à Educação Ambiental em uma perspectiva crítica e emancipatória.

Justifica-se a utilização da abordagem qualitativa por acreditar que ela tem uma característica particular, que é o ambiente onde ocorre. Para tal, de acordo com Chizzotti (2003), a abordagem qualitativa parte do fundamento de que há uma relação dinâmica entre 0 mundo real e o sujeito, uma interdependência viva entre o mundo objetivo e a subjetividade do sujeito.

A coleta de dados na fase inicial foi bibliográfica e documental, o que permitiu uma visão mais ampla do objeto de pesquisa e das questões do estudo, para então seguir uma delimitação.

Alguns métodos foram utilizados para responder os objetivos da pesquisa, sendo o primeiro passo a entrega de um questionário para trinta (30) discentes, de um total de 60 alunos matriculados nos cursos técnicos do Senac, maiores de 18 anos, dos cursos técnicos de Administração e Logística, para poder identificar a visão dos educandos em relação ao Sistema de Gestão Ambiental e as sugestões de melhoria do processo, para aprimorar a atuação dos docentes na práxis da Educação Ambiental.

O segundo passo foi à entrega de questionário a oito (8) professores que ministram aulas nos cursos técnicos de Administração e Logística, de um total de 18 professores, do SENAC de São José dos Campos, com questões semiestruturadas, referentes às temáticas: meio ambiente, Educação Ambiental e Sistema de Gestão Ambiental, para então, avaliar suas concepções teóricas metodológicas sobre os temas, sendo as respostas estudadas por meio da análise de conteúdo.

A análise de conteúdo é uma técnica de análise das comunicações, que irá analisar o que foi dito nas entrevistas ou observado pelo pesquisador. $\mathrm{Na}$ análise do material, busca-se classificá-los em temas ou categorias que auxiliam na compreensão do que está por trás dos discursos.

O investigador tenta construir um conhecimento analisando a disposição e os termos utilizados pelo locutor. O investigador necessita assim de utilizar métodos de análise de conteúdo que implicam a aplicação de processos técnicos relativamente precisos, não se devendo preocupar apenas com aspectos formais, estes servem somente de indicadores de atividade cognitiva do locutor.

A análise de conteúdo surge do positivismo, que usa como base a metodologia das ciências exatas para estudar as ciências humanas. Seguindo esse princípio, teorias sobre a vida social deveriam ser formuladas de forma rígida, linear e metódica, com base em dados verificáveis. Sendo assim, dados não quantificáveis, como intenções, eram evitados.

A análise da coleta de dados das observações participantes foi à análise de conteúdo dos resultados textuais (falas, relato das observações) com uma 
parte descritiva, registrando detalhadamente o que ocorreu em cada encontro nas aulas observadas e uma parte mais reflexiva, em que incluiu observações pessoais do pesquisador. A análise considerou o contexto do estudo, articulou as respostas do questionário e as observações participantes com o referencial teórico.

Em relação ao estudo de caso, os autores Bogdan e Biklen (1994) afirmam que ele pode ser representado como um funil, em que o início do estudo é sempre a parte mais larga. Segundo esses autores, nos estudos de caso, a melhor técnica de recolher dados consiste na observação participante, sendo o foco de estudo uma organização particular.

Os educadores e educandos participantes dos encontros, não tiveram seus nomes identificados nas falas transcritas, os educadores foram identificados por ordem alfabética, e os educandos por ordem numérica, obedecendo à ética da pesquisa.

A pesquisa foi submetida à Plataforma Brasil, encaminhada ao comitê de ética da Universidade do Vale do Paraíba (UNIVAP), com parecer favorável de número 2.359.217.

\section{O contexto da pesquisa: apresentação do SENAC de São José dos Campos (SP)}

O Serviço Nacional de Aprendizagem Comercial (SENAC) é uma instituição educacional de direito privado e sem fins lucrativos, criada pelo governo federal por meio dos Decretos-Lei no 8.621 e 8.622, de 10 de janeiro de 1946. Tal iniciativa deveu-se ao esforço do empresariado do comércio que, inspirado na bem-sucedida criação do Serviço Nacional de Aprendizagem Industrial (SENAI) em 1942, na área da indústria, reivindicou e obteve do governo a incumbência para organizar, manter e administrar um organismo nacional de formação profissional para o setor terciário.

Dessa forma, foi atribuído à Confederação Nacional do Comércio o encargo de implantar e desenvolver, em todo o País, escolas de aprendizagem comercial para empregados e candidatos a emprego no setor comercial. Para viabilizar essa imensa tarefa, a legislação que deu origem ao SENAC, e posteriormente ao SESC, Serviço Social do Comércio (que visa à valorização do trabalhador, oferecendo atividades de caráter educativo nas áreas de esporte, saúde, cultura, lazer e cidadania), determinou que o comércio contribuísse com o correspondente a $1 \%$ da sua folha de pagamento para a manutenção do SENAC e com 1,5\% para o SESC.

Por ter sido criado por decreto-lei, é comum pensar-se que o SENAC seja uma instituição pública. Entretanto, trata-se de uma entidade de direito privado, cuja organização e administração estão delegadas, por lei, à Confederação Nacional do Comércio, órgão máximo de representação sindical patronal do setor de comércio e serviços. 
Seis meses após o surgimento do SENAC Nacional foi criado o SENAC São Paulo, o primeiro a iniciar suas atividades no País com a eleição do Conselho Regional do Estado de São Paulo em 13 de julho de 1946. De início, a atuação do SENAC São Paulo estava voltada, exclusivamente, para a formação de aprendizes, menores a partir de 14 anos encaminhados pelas empresas.

O SENAC São José dos Campos forma profissionais qualificados para atuar no mercado de trabalho desde 1992, quando foi inaugurado. A terceira unidade construída no Vale do Paraíba, seguindo Taubaté e Guaratinguetá, transformou $5660 \mathrm{~m} 2$ de terreno em um centro de conhecimento para o trabalho.

A escola também busca formar cidadãos. Todos os cursos técnicos oferecidos apresentam em sua grade de ensino as disciplinas de Responsabilidade Social e Meio Ambiente. Além disso, programas como a Educação para o Trabalho e do Projeto Profissão orientam o profissional e a comunidade com informações e conhecimentos relacionados ao $3^{\circ}$ setor. técnicos.

Atualmente, a unidade apresenta cursos livres, de qualificação e

\section{Resultados e discussão}

\section{Práticas da Educação Ambiental integradas ao SGA no SENAC}

Nas salas de aula são evidenciados os quadros de comunicação da Gestão Ambiental da unidade, demonstrado na Figura 1, onde estão descritas as diretrizes do programa e as suas aplicações.

Os educandos têm acesso às principais diretrizes do sistema, tendo como objetivo a integração e participação do estudante no processo da conscientização ambiental.

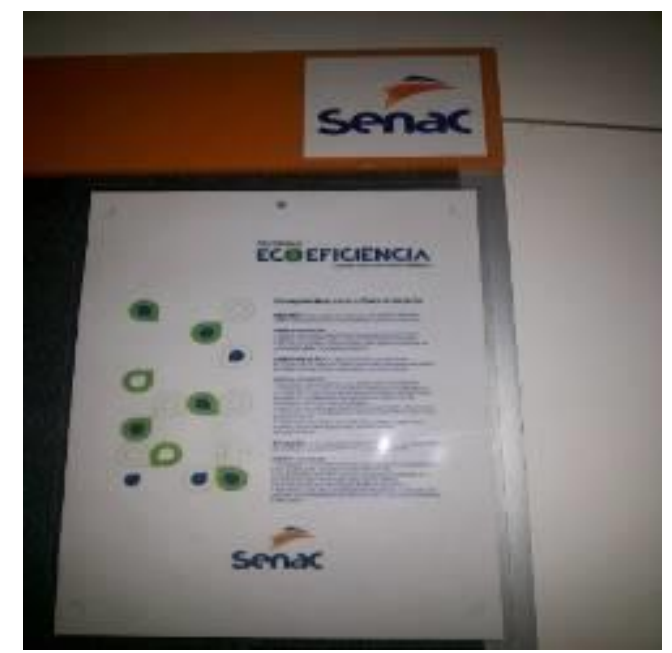

Figura 1: Quadro de gestão a vista do SGA. Fonte: Autoria Própria (2017).

Revbea, São Paulo, V. 14, № 1: 132-148, 2019.

revista brasileira 
$\mathrm{Na}$ escada pedagógica da unidade, na Figura 2, nos degraus estão expostas algumas frases de impacto da cultura do SGA. Pode-se observar que os educandos identificam os tópicos fundamentais da gestão dos resíduos da unidade e questões ambientais.

Pode-se observar também que essa ação de comunicação é importante, pois os educandos ficam curiosos por saber mais informações do programa, além de ser usado em estratégias educacionais dos docentes, para interação pedagógica da tomada de consciência crítica de como usar com responsabilidade e consciência os bens naturais, além de descartar os resíduos nos pontos de coleta adequados.

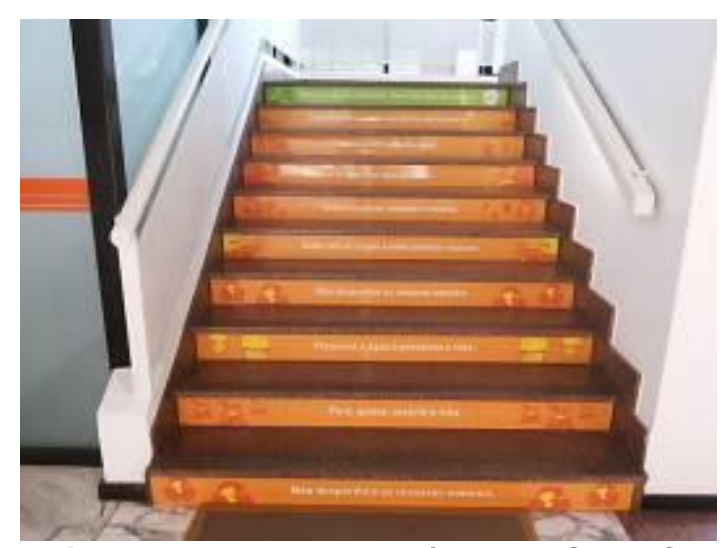

Figura 2: Escada pedagógica do SENAC. Fonte: Autoria Própria (2017).

Há coletores de resíduo reciclável e não reciclável em toda a escola, para o descarte adequado de diferentes resíduos, como papel, metal, vidro e plástico.

$\mathrm{Na}$ Figura 3, se pode identificar que os educandos são orientados a descartar os resíduos no coletor adequado, aprendem a descartar os resíduos na prática, pois precisam descartar corretamente nos coletores espalhados pela unidade.

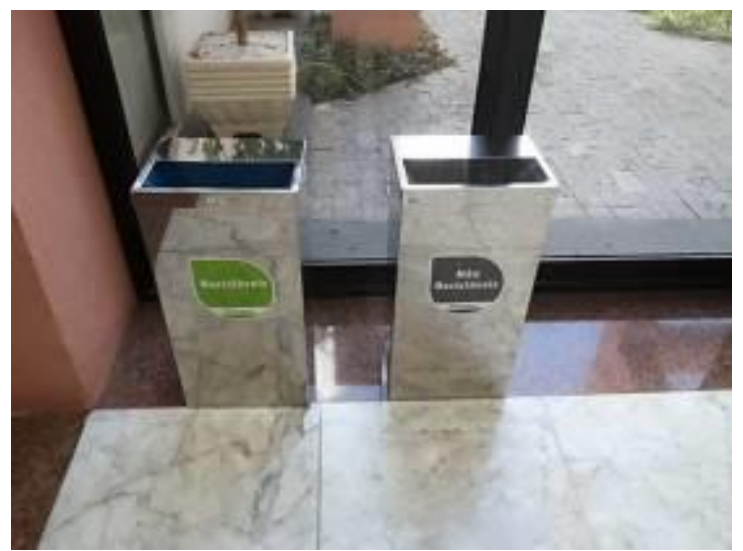

Figura 3: Coletores de resíduos do SENAC. Fonte: Autoria Própria (2017). 
A compostagem é o processo biológico de valorização da matéria orgânica, seja ela de origem urbana, doméstica, industrial, agrícola ou florestal, e pode ser considerada como um tipo de reciclagem do lixo orgânico.

Trata-se de um processo natural em que os micro-organismos, como fungos e bactérias, são responsáveis pela degradação de matéria orgânica.

$\mathrm{Na}$ Figura 4, pode-se observar que os estudantes do SENAC fazem visitas constantes a compostagem, aprendendo na prática o processo.

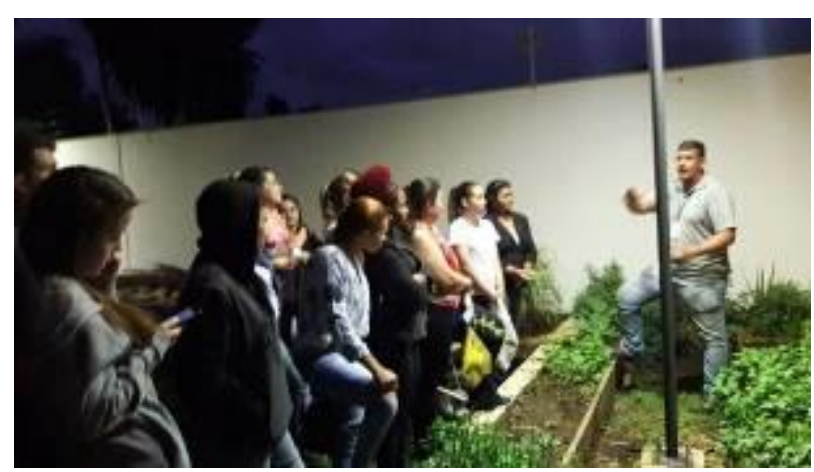

Figura 4: Aula prática na compostagem do SENAC.

Fonte: Autoria Própria (2017).

O SENAC ainda possui a horta pedagógica como observado na Figura 5. Os educandos aprendem a cultivar algumas culturas de plantas, para posteriormente serem utilizadas na cozinha pedagógica da unidade, durante as aulas de gastronomia.

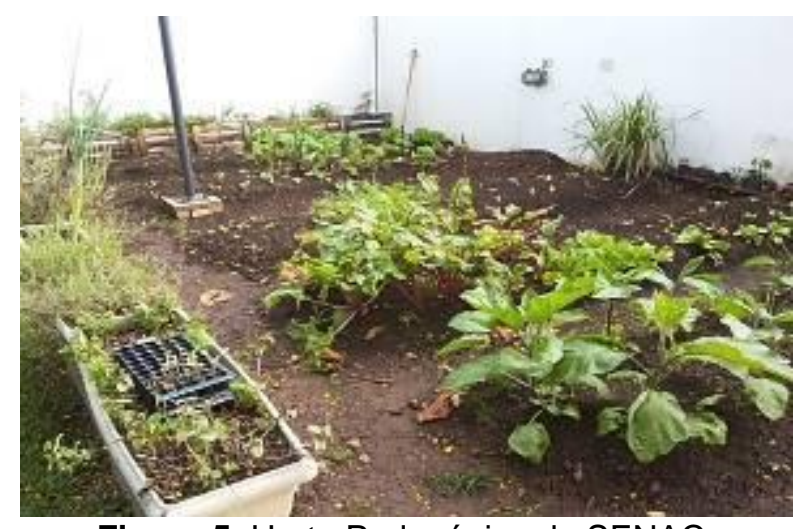

Figura 5: Horta Pedagógica do SENAC.

Fonte: Autoria Própria (2017).

Os informativos do SGA estão presentes nos banheiros da unidade, conforme Figura 6, com objetivo de que os educandos aprendam a usar conscientemente a água e a energia. Pode-se evidenciar que o educando é protagonista no processo de sustentabilidade da escola. 


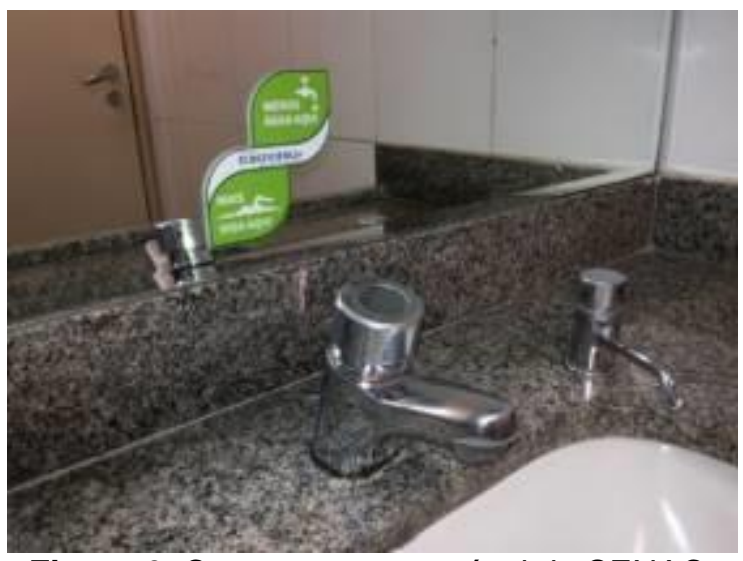

Figura 6: Consumo responsável do SENAC.

Fonte: Autoria Própria (2017).

O SENAC estabeleceu metas para impressões por educador e educando, com objetivo de diminuir o uso excessivo de papel na unidade.

A participação efetiva dos educandos favoreceu a consciência da necessidade da diminuição do uso do papel. Pode ser evidenciado que a maioria dos estudantes planejaram as entregas dos trabalhos de formas mais sustentáveis, como por exemplo, no formato digital.

Outra ação sustentável observada foi o fim do uso do copo descartável na máquina de café expresso da sala dos professores, os docentes receberam canecas personalizadas para poder reutilizar, reduzindo assim a geração de resíduos na unidade.

A Cooperativa de Reciclagem de Materiais São Vicente de Paula é responsável pelo encaminhamento dos resíduos sólidos do SENAC, de papel, plástico, metal, vidro e óleo vegetal usado, para uma destinação correta e eficiente.

Com esta atividade a cooperativa gera trabalho e renda para mais de 30 famílias, que tiram seu sustento das atividades desenvolvidas na coleta, triagem e venda dos materiais reciclados.

Os estudantes visitam com frequência a cooperativa e aprendem a desenvolver trabalhos práticos de melhoria da cooperativa em relação ao respeito do meio ambiente, além de promover a dignidade do trabalho, viabilizando cidadania aos seus cooperados.

Em relação às práticas da Educação Ambiental integradas ao SGA no SENAC, a EA crítica é a condição para a emancipação dos sujeitos, para a formação de sujeitos autores de sua história de vida, capazes de identificar e problematizar questões socioambientais e agir-refletir-agir sobre elas. Paulo Freire defende, em toda sua obra, que a captação e a leitura que o homem faz dos dados objetivos de sua realidade precisam ser necessariamente críticas. 


\section{Dando voz aos sujeitos da aprendizagem: pesquisa desenvolvida com os educandos}

A primeira etapa da pesquisa foi realizada através de questionário com trinta (30) educandos do SENAC São José dos Campos, apresentando os seguintes resultados.

Pode-se evidenciar que $90 \%$ dos educandos conhecem o Sistema de Gestão Ambiental do SENAC, e 10\% não têm conhecimento do programa.

O preceito fundamental do Sistema de Gestão Ambiental é a comunicação dos usuários internos e externos de uma empresa, nesse aspecto a unidade cumpre com as exigências da Norma ISO 14001.

Os dados evidenciados demonstram que a maioria dos estudantes conhecem o programa, porém se faz necessário aprimorar o processo de comunicação do Sistema de Gestão Ambiental, objetivando a melhoria continua do processo e uma melhor divulgação aos educandos da escola.

Os professores do SENAC são os protagonistas dessa comunicação com os educandos, por isso precisam alinhar a prática pedagógica das aulas com ações de divulgação do SGA na unidade.

Paulo Freire (1996) ressalta que a construção do saber acontece de forma conjunta, em que o educador se aproxima dos conhecimentos prévios dos educandos, para, a partir desses, construir conhecimentos significativos com os educandos, criando um espaço/tempo no qual os educandos tenham voz, possam participar efetivamente e construírem sua autonomia.

Os educandos não são recipientes passivos dos conteúdos, são sujeitos e construtores de conhecimento, investigadores críticos e desafiadores, em diálogo com o educador. O educador se educa com o conteúdo que o educando traz. Uma situação de construção de conhecimento se dá entre educadores e educandos, de A com B, mediatizados por objetos de conhecimento com temáticas significativas.

Nos dizeres de Freire (2005, p.84):

A educação autêntica, repitamos, não se faz de $A$ para $B$ ou de A sobre $B$, mas de $A$ com $B$, mediatizados pelo mundo. Mundo que impressiona e desafia a uns e a outros, originando visões ou pontos de vista sobre ele. Visões impregnadas de anseios, de dúvidas, de esperanças e desesperanças que implicam temas significativos, à base dos quais se constituirá o conteúdo programático da educação.

Pode ser observado que os educandos reconhecem a importância do programa SGA para o SENAC São José dos Campos, como um centro de referência da Educação Ambiental prática e transformadora da sociedade. 
Pode-se evidenciar que $90 \%$ dos educandos compreendem a importância de um sistema de gestão ambiental para o SENAC, como um polo de referência em educação e gestão do meio ambiente, porém 10\% não compreendem a importância do programa para a unidade.

As práticas da Educação Ambiental são reconhecidas por vinte e seis (26) educandos, quatro (4) não concordam que o SENAC tem trabalhado de forma satisfatória com a Educação Ambiental e justificam não conhecer 0 programa, a figura10 apresenta os resultados.

Pode-se constatar que $87 \%$ dos educandos avaliam que o SENAC é eficiente no ensino da Educação Ambiental, e 13\% não identificam a importância do SGA na escola.

Os estudantes reconhecem como uma prática em relação ao aspecto das práticas da Educação Ambiental aplicados pela unidade.

Um total de $80 \%$ dos educandos observam que são desenvolvidas práticas em sala de aula durante o curso, mas 13\% dos estudantes responderam que não são aplicadas e $7 \%$ não souberam responder. Esse resultado ratifica a necessidade de uma melhor integração dos docentes em relação às atividades práticas da Educação Ambiental.

As sugestões dos educandos foram ao sentido de inserir mais atividades práticas integradas as práticas do SGA, relataram que alguns professores acabam deixando de trabalhar as questões referentes a Educação Ambiental em suas aulas.

Pode-se evidenciar que $90 \%$ dos educandos compreendem a importância do tema ambiental na sua formação profissional e social, porém 10 \% da amostra não reconhecem a inserção do tema ambiental nos cursos técnicos. A educação profissional prepara o estudante para a prática profissional e a questão ambiental afeta diretamente suas atividades e convivência social na comunidade onde moram.

Os educandos acreditam na possibilidade da integração da Educação Ambiental com o SGA e apontam como sugestão a melhor integração dos professores em relação ao trabalho em sala de aula.

Segundo os educandos entrevistados alguns professores acabam deixando de realizar práticas na unidade, quando aborda o tema ambiental, o que justifica a necessidade de replanejamento das aulas para um melhor aproveitamento do conteúdo, objetivando maior integração com o Sistema de Gestão Ambiental.

O educador que escuta os educandos, dialoga, ensina e aprende com eles, considera as curiosidades e necessidades desses sujeitos e delas parte para a organização e desenvolvimento das aulas. Assim, os educandos são provocados a transitar da curiosidade ingênua para a curiosidade epistemológica, sem a qual, permaneceriam com uma leitura menos criticada crise ambiental, das desigualdades e injustiças sociais a ela associadas. 
Para Freire (1980, p.39):

É preciso que a educação esteja - em seu conteúdo, em seus programas e em seus métodos - adaptada ao fim que se persegue: permitir ao homem chegar a ser sujeito, construir-se como pessoa, transformar o mundo, estabelecer com os outros homens relações de reciprocidade, fazer a cultura e a história.

Os fazeres inovadores na prática pedagógica do professor com a construção de conhecimentos significativos, favorecem a aprendizagem das experiências, das vivências, das relações, da reflexão crítica, das tensões e das contradições existentes nos contextos sociais e ambientais.

A sociedade precisa de educadores que enfrentem tensões no campo do trabalho docente, o que exige conhecimentos aliados ao compromisso profissional, que é também social.

Freire (2005) entende o educador como um sujeito social, construtor e transformador da realidade histórica, em que vive, o que significa que a história é uma construção humana, é um tempo de possibilidades.

Para Freire, a possibilidade de construção de uma sociedade mais solidária está também na possibilidade de construção de uma educação críticoemancipatória, pois, em seus dizeres: se a educação sozinha não transforma a sociedade, sem ela tampouco a sociedade muda (FREIRE,2000, p.67).

\section{A percepção dos professores sobre o Sistema de Gestão Ambiental e a prática pedagógica}

A segunda etapa da pesquisa foi realizada através de questionário com oito (8) professores do SENAC que ministram aulas nos cursos técnicos de Administração e Logística, apresentando os seguintes resultados.

Os docentes entrevistados em sua totalidade conhecem o Sistema de Gestão Ambiental do SENAC, conforme figura 13, e acreditam na possibilidade de integrar a temática ambiental com a prática das ações do SGA.

Um total de $100 \%$ dos professores entrevistados declara que utilizam o Sistema de Gestão Ambiental como estratégia da Educação Ambiental em sala de aula.

Os docentes reconhecem a importância da Educação Ambiental no currículo dos cursos técnicos profissionais da unidade, não apenas para cumprir uma legislação, mais uma oportunidade de trabalhar o tema ambiental em práticas do SGA da unidade, para assim formas estudantes críticos e conscientes do seu papel na sociedade em relação a do meio ambiente.

A Educação Ambiental presente nas práticas pedagógicas e nos projetos educacionais, como uma dimensão da educação, tende a promover reflexões e

revista brasileira educação ambiental 
ações acerca dos problemas ambientais que a sociedade enfrenta, pois segundo Paulo Freire (1996), o papel do educador não é encher os educandos de conhecimentos, mas orientá-los a construírem um pensamento crítico, que possibilite a reflexão sobre as relações sociais e destas com o meio natural, em suas problemáticas e alternativas de ações.

Segundo os docentes entrevistados, o interesse dos educandos dos cursos técnicos em relação à Educação Ambiental se intensifica quando aprendem a utilizar a teoria na prática, os conhecimentos na prática com a Educação Ambiental transformadora, aumentando a representatividade dos educandos em ações na escola.

O resultado da pesquisa demonstra que não basta a inclusão da temática da Educação Ambiental na formação dos docentes; observa-se que a mesma necessita ser em uma perspectiva crítico-humanizadora compreendida, neste trabalho, no quefazer docente orientador e incentivador de mudanças de atitudes e valores. Essas mudanças não são processos naturais, mas, sim, resultantes de escolha após análise e reflexão crítica pessoal e com os outros - afinal, os homens são seres de relação. Assim, para Freire, são seres da:

Consciência de e ação sobre a realidade são inseparáveis constituintes do ato transformador pelo qual homens $e$ mulheres se fazem seres de relação. A prática consciente dos seres humanos, envolvendo reflexão, intencionalidade, temporalidade e transcendência, é diferente dos meros contatos dos animais com o mundo (FREIRE, 2007, p. 78).

Os docentes fizeram sugestões para que o currículo do SENAC desenvolva melhor a integração da Educação Ambiental com o SGA da unidade, sendo estas:

- Melhorar a integração dos estudantes quando iniciam seus estudos na unidade, apresentando nos primeiros dias de aula os principais pilares do Sistema de Gestão Ambiental do SENAC;

- Cronograma de visitas técnicas em ações sustentáveis de outras empresas, para apresentar a realidade prática da gestão ambiental;

- Promover um melhor envolvimento de professores nas ações do Sistema de Gestão Ambiental, com uma integração mais eficiente e participação dos encontros do grupo do SGA, buscando um maior engajamento e efetividade nas ações. 


\section{Propostas de intervenção do SGA com as práticas pedagógicas da Educação Ambiental no SENAC}

Nessa proposta, a Educação Ambiental crítica foi pensada estrategicamente nas ações práticas do Sistema de Gestão Ambiental, com o objetivo de mobilizar sujeitos, saberes e práticas em favor de uma educação emancipatória.

A proposta de integração precisa considerar as concepções, princípios e representações dos docentes e discentes em relação à temática socioambiental, numa tentativa de potencializar as ações já empreendidas localmente, no esforço de sistematização e planejamento de práticas mais críticas.

Pensar a prática, a partir de uma leitura crítica da realidade, favorece avançar cada vez mais para uma tomada de consciência que impulsiona o ser humano a agir, a buscar a transformação da realidade.

Ao perfilar-se nos caminhos híbridos do conhecimento e da impertinência, a EA desperta enorme expectativa renovadora do sistema de ensino, da organização e dos conteúdos escolares, convidando a uma revisão da instituição e do cotidiano escolar mediante os atributos da transversalidade e da interdisciplinaridade. Essa é uma tarefa bastante ousada. Trata-se de convidar a escola para a aventura de transitar entre saberes e áreas disciplinares, deslocando-a de seu território já consolidados rumo a novos modos de compreender, ensinar e aprender (CARVALHO, 2006, p.125).

A seguir, serão apresentadas indicações para uma proposta de integração da Educação Ambiental com as ações práticas do SGA no SENAC de São José dos Campos, desenhada coletivamente por educadores e educandos.

Ações possíveis no sentido de avançar o trabalho com uma Educação Ambiental crítica, na escola, foram propostas pelos professores e educandos dos cursos técnicos de Administração e Logística, em reuniões para as quais foram convidados ao final dessa pesquisa. No elenco dessas ações figuram:

a) Integração de professores nas diretrizes do Sistema de Gestão Ambiental da unidade.

b) Ampliação da rede de conexão da escola com a comunidade, para conhecer e aplicar os conhecimentos do SGA nas empresas da região.

c) Discussão de relatos de experiências do trabalho com Educação Ambiental transformadora.

d) Consolidação de grupos de estudos em Educação Ambiental integradas a ações práticas do SGA na escola.

e) Promoção de Seminários e Workshops sobre o Sistema de Gestão Ambiental do SENAC. 
A formação dos educadores é um processo necessário para a integração da Educação Ambiental com o SGA, a transformação busca se inserir em uma tradição crítica que tem como exigência o reconhecimento do outro como sujeito, sua visão de mundo e necessidades, como pontos de partida para a prática pedagógica da Educação Ambiental.

Considerando-se os contextos da educação formal e da pesquisa científica, REIGOTA (2004, p.35) entende que a Educação Ambiental.

É preciso que o planejamento das aulas se aprofunde no sentido de investigar como a questão relativa à gestão ambiental, possa ser geradora de ações práticas e solidárias, e de uma compreensão mais crítica do conhecimento produzido na escola, que vai possibilitar a conscientização ambiental dos discentes, compartilhando conhecimentos com os novos estudantes dos cursos do SENAC e com a comunidade.

Esse processo sempre inacabado e, portanto, processo da existência humana vai refazendo dialeticamente a história; daí a defesa freireana de uma história como libertação.

Freire (2001) afirma que "assumirmo-nos como sujeitos e objetos da História nos torna seres da decisão, da ruptura. Seres éticos" (FREIRE, 2001, p.40).

A práxis libertadora é dialógica, já que a educação libertadora tem sua razão de ser, e segundo Freire (2005, p.67):

No seu impulso inicial conciliador. Daí que tal forma de educação implique a superação da contradição educadoreducandos, de tal maneira que se façam ambos, simultaneamente, educadores e educandos.

Sob os pontos apresentados a proposta tem o objetivo de sensibilizar para conscientizar os educandos, funcionários e professores sobre sua responsabilidade em provocar mudanças na sociedade; construindo valores, hábitos e estilos de vida para um mundo mais justo e sustentável; fortalecendo a capacidade de reflexão crítica, valorizando a vida, a diversidade humana e natural como principal riqueza. 


\section{Conclusão}

Com as evidências apresentadas pode-se concluir que o Sistema de Gestão Ambiental é uma importante estratégia da Educação Ambiental no SENAC de São José dos Campos, mas ainda precisa de aperfeiçoamento e estudo.

O primeiro impacto da Educação Ambiental na unidade é a comunicação do SGA, fomentando a busca pelo conhecimento, para a participação efetiva desse educando no Sistema de Gestão Ambiental da escola, com objetivo de formar um cidadão ambientalmente consciente e atuante na sociedade em que vive.

Importante salientar que todo o processo avaliativo da integração dos processos deverá ser feito coletivamente, envolvendo educadores e educandos, tomando por base as avaliações descritas nas propostas. Assim, tanto educadores quanto educandos poderão avaliar em que grau os objetivos propostos foram alcançados e direcionar ações para melhoria do processo, numa perspectiva de ação e transformação em relação às dificuldades encontradas.

O educando é o protagonista do processo na escola, tendo a oportunidade de participar ativamente do SGA, de aprender na prática com os erros e acertos por meio de novas reflexões e situações de aprendizagem.

Os professores são importantes sujeitos no processo de integração do SGA com a Educação Ambiental da escola, sendo responsáveis pelas ações que partem do plano de aula estruturado para a participação prática dos educandos.

Faz-se importante uma intervenção nas práticas em sala de aula, e um dos fatores principais para a estratégia dar certo é a formação dos docentes, para aprimorar as suas aulas da Educação Ambiental, buscando a participação e a conscientização dos estudantes do SENAC.

Entende-se que a pesquisa pode proporcionar ao educador uma mudança de postura e uma oportunidade de repensar sua prática pedagógica, pois ao alinhar a teoria com a prática, a partir da realidade local, é possível construir com os discentes uma nova consciência e atitudes com relação ao cuidado com o ambiente em que vivem.

\section{Referências}

BARDIN, L. Análise de Conteúdo. Lisboa, Portugal; Edições 70, LDA, 2009.

BRASIL. Constituição (1988). Constituição [da] República Federativa do Brasil. Brasília: Senado Federal, 1988.

BRASIL. Lei no 9795, de 27 de abril de1999. Dispõe sobre a Educação Ambiental, instituía Política Nacional de Educação Ambiental e dá outras providências. Diário Oficial [da] República Federativa do Brasil, Brasília, 28 abril. 1999. Seção 1, p.1.

revista brasileira educação ambiental 
BRASIL. Resolução no2, de 15 de junho de 2012. Estabelece as Diretrizes Curriculares Nacionais para a Educação Ambiental. Diário Oficial da União. Brasília: DOU, 2012.

CARVALHO, I.C.M. Qual Educação Ambiental? Elementos para um debate sobre Educação Ambiental e extensão rural. Agroecologia e Desenvolvimento Rural Sustentável, Porto Alegre, v.2, n.2, abr./jun.2001, p. 43-51.

CARVALHO, I.C.M. Educação Ambiental: a formação do sujeito ecológico. São Paulo: Cortez, 2006.

CHIZZOTTI, A. Pesquisa em ciências humanas e sociais. 6.ed. São Paulo: Cortez, 2003.

DENZIN K. N.; LINCOLN, Y,S. (Orgs). O planejamento da pesquisa qualitativa: teorias e abordagens. Trad. Sandra Regina Netz - Porto Alegre: Artmed, 2006.

FREIRE, P. Conscientização: Teoria e prática da libertação - uma introdução ao pensamento de Paulo Freire. 4.ed. São Paulo: Moraes, 1980.

FREIRE, P. Educação e mudança: Rio de Janeiro: Paz e Terra,1981.

FREIRE, P. Por uma pedagogia da pergunta: Rio de Janeiro: Paz e Terra,1995.

FREIRE, P. Pedagogia da autonomia: saberes necessários a prática educativa. São Paulo: Paze Terra,1996.

FREIRE, P. Educação como prática de liberdade. 24. ed. Rio de Janeiro: Paz e Terra, 2000a.

FREIRE, P. A educação na cidade. 4. ed. São Paulo: Cortez, 2000b.

FREIRE, P. Pedagogia da indignação: cartas pedagógicas e outros escritos. São Paulo: UNESP, 2000.

FREIRE, P. À sombra desta mangueira. 6.ed. São Paulo: Olho d'Água,2001.

FREIRE, P. Pedagogia do oprimido: 49.ed. Rio de Janeiro: Paz e Terra,2005.

FREIRE, P. Ação cultural para a liberdade: e outros escritos. 12. ed. Rio de Janeiro: Paz e Terra, 2007.

REIGOTA, M. Desafios à Educação Ambiental escolar. In: JACOBI, Pedro et al. (Orgs.). Educação, meio ambiente e cidadania: reflexões e experiências. São Paulo: SMA, 1994.

REIGOTA, M. Floresta e a Escola: por uma Educação Ambiental pósmoderna. São Paulo: Cortez, 1999.

REIGOTA, M. O que é Educação Ambiental. 2. ed. revista e ampliada. Coleção Primeiros Passos. São Paulo: Brasiliense,2009.

SENAC, Norma para o Sistema SENAC de Gestão Ambiental. 6ª Versão. Ano 2015. 